\title{
MORPHOMETRIC STUDY OF GASTRIC MUCOSA IN DOGS SUBMITTED TO PROXIMAL GASTRIC VAGOTOMY, SPLENECTOMY OR PROXIMAL GASTRIC VAGOTOMY ASSOCIATED WITH SPLENECTOMY ${ }^{1}$
}

\author{
Carlos Augusto Real Martinez ${ }^{2}$ \\ Jaques Waisberg ${ }^{3}$ \\ Rogério Tadeu Palma ${ }^{4}$ \\ Fabiana Zangiácomo da Silva ${ }^{5}$ \\ Gustavo Cimerman ${ }^{5}$ \\ Fabio Schmidt Goffí ${ }^{6}$
}

\begin{abstract}
Martinez CAR, Waisberg J, Palma RT, Silva FZ, Cimerman G, Goffi FS. Morphometric study of gastric mucosa in dogs submitted to proximal gastric vagotomy, splenectomy or proximal gastric vagotomy associated with splenectomy. Acta Cir Bras [serial online] 2002 Sept-Oct;17(5). Available from URL: www.scielo.br/acb.
\end{abstract}

ABSTRACT - Objective: The aim of the present study was to evaluate the effects of total splenectomy and proximal gastric vagotomy (PGV) isolated or associated to the vascularization of the stomach. Methods: Twenty-eight dogs were distributed in: group A - animals undergoing laparotomy and gastric manipulation; group B - animals undergoing PGV; group C - animals undergoing PGV and splenectomy; and group D - animals undergoing splenectomy alone. All animals were sacrificed on the 7th postoperative day, and immediately followed by infusion of xanthene dye into the thoracic aorta. On the gastric mucous surface, the formation of stained areas and other areas lacking staining was measured by millimeter squares, planimetry and the computerized morphometry method. Results: The formation of an area lacking in staining along the lesser gastric curvature was seen in all animals of groups B and C, which was significantly increased in group C, although in groups A and D such areas were not observed. Conclusion: These results showed that, in animals with splenectomy, the vascularization of the stomach was capable of perfusing the whole organ surface, but in animals with PGV alone or associated with splenectomy there was a notable decrease in blood supply throughout the area of the lesser gastric curvature, which suggests the ischemic impairment of this region.

KEY WORDS - Splenectomy. Vagotomy. Proximal gastric vagotomy. Stomach.

1. From the Posgraduate Program in Surgical Gastroenterology - Instituto de Assistência Médica ao Servidor Público Estadual IAMSPE (São Paulo -SP).

2. Associated Professor - Department of General Surgery, Faculdade de Medicina da Universidade São Francisco (Bragança Paulista - SP).

3. Assistant Professor - Department of Gastrointestinal Surgery, Faculdade de Medicina do ABC (Santo André - SP). Department of Gastrointestinal Surgery, Hospital do Servidor Público Estadual (São Paulo - SP).

4. Master in Gastrointestinal Surgery - Instituto de Assistência Médica ao Servidor Público Estadual IAMSPE (São Paulo - SP).

5. Student - Faculdade de Medicina do ABC (Santo André - SP)

6. Director - Postgraduate Program - Instituto de Assistência Médica ao Servidor Público Estadual - IAMSPE (São Paulo - SP). 


\section{INTRODUCTION}

The stomach is seen to be resistant to postoperative ischemic phenomena due to its significant extrinsic blood supply and rich submucosal capillary network. With the development of a wide variety of surgical procedures that can severely interfere with the blood supply, postoperative gastric ischemia has become recognized with greater frequency ${ }^{1}$. Ischemia and, possibly, necrosis of the gastric wall may follow several interventions undertaken on the stomach. Prominent among such interventions is gastrectomy ${ }^{1}$, gastroplas$\mathrm{ty}^{2}$, fundoplication ${ }^{3}$ and proximal gastric vagotomy $(\mathrm{PGV})^{4,5,6}$

Associated surgical procedures that reduce stomach irrigation may increase the possibilities for this phenomenon to occur. Among the interventions capable of reducing the blood supply to a operated stomach, splenectomy is the one that gives greatest risk due to the possibility it has for causing gastric necrosis and because the intraoperative accidents are relatively frequent following this procedure ${ }^{7,8}$.

The objective of the present study was to evaluate the formation of areas in the stomach potentially subject to ischemic phenomena, in dogs undergoing splenectomy and PGV isolated or simultaneous.

\section{METHODS}

Twenty-eight mongrel dogs without any selection regarding weight or sex were operated. After a 12hour fast, the animals underwent anesthesia with etil(1metil-butil) sodium barbituratic (Nembutal), diluted to $0.9 \%$ in a physiological solution, at a dosage of 30 $\mathrm{mg} / \mathrm{Kg}$ applied intravenously. The dogs were divided into four experimental groups denominated group $\mathrm{A}$ or control group (six dogs), in which traction of the stomach and spleen was performed; group B (nine dogs): animals that underwent PGV; group $\mathrm{C}$ (nine dogs): animals that underwent PGV in association with splenectomy; group D (four dogs): animals that underwent splenectomy alone.

The draw to determine the animal to be operated on was made immediately before the surgery. The opening on the abdomen wall was performed in a standard manner for the four groups, by means of a median incision that extended from the xiphoid appendix to the umbilical scar. The operational sequence thereafter depended on the group that the animal belonged to.

In group $\mathrm{A}$, the stomach was placed under traction with the aid of an orogastric probe positioned along the greater curvature for a period of 45 minutes.
Simultaneously, the spleen was pulled out of its normal anatomical position and kept under traction for the same length of time. Next, the organs were replaced in the abdominal cavity and the surgical incision was sutured in layers.

In group B, dissection and ligature of the vesselnerve bundles that initiated in the lesser curvature from the first antral branch was started after identifying the anterior gastric nerve. These ligatures were performed under direct view in the cranial direction, until the esophagus-stomach transition was reached. After release the anterior gastric nerve, the same procedure was performed to release the posterior gastric nerve. After concluding the operation, the lesser curvature was reviewed, observing that it had not become reperitonized. The incision was closed in the same way as done for the preceding group.

In group $\mathrm{C}$, the vagotomy was performed in the same way as for the preceding group. After concluding the PGV, the splenectomy was performed with ligature of the vessels that head towards the organ, at a standardized distance of $3 \mathrm{~cm}$ from the splenic hilum. After concluding the operation, the abdominal wall was sutured in layers using the same technique as employed in the preceding groups.

For the animals in group $\mathrm{D}$, the removal of the spleen was performed using the same technique as in the preceding group. The closing of the abdominal wall also observed the same methodology as utilized in the preceding groups.

After completing the surgery, the animals were kept in individual cages and standardized food and water were supplied, starting from the day after the operation. During the night of the sixth postoperative day, the dogs were again kept under fasting conditions for the sacrifice, which for all groups was always performed on the seventh day.

On the day scheduled for the sacrifice, the animals received the same dosage of anesthesia as utilized at the time of the operation. Next, the abdominal cavity was reopened along the line of the previous incision, but extending it as far as possible in the caudal direction. After making an appraisal of the cavity, the abdominal aorta was identified and repositioned just above the origin of the renal arteries. Next, the portal vein was identified and isolated. After concluding this stage, the dogs, still under anesthesia, were exsanguinated due by sectioning the carotid arteries. When the cardiac sounds could no longer be detected, sternotomy was performed and the thoracic aorta was identified $10 \mathrm{~cm}$ above the hiatus of the diaphragm. A catheter was installed at this point and it was connected to a pump 
that performed infusion of staining substance at a constant pressure of $12 \mathrm{~mm} / \mathrm{Hg}$.

The staining substance utilized for the infusion into the thoracic aorta was hydrochloroethyl ethanolamine (Rhodamine) at a dosage of $5 \mathrm{~g} / \mathrm{L}$. The portal vein, which had been isolated at the outset, was sectioned and catheterized using a $10 \mathrm{Fr}$ polyethylene catheter, and the abdominal aorta was tied. The process of infusion was begun and it was only halted when the staining substance was no longer recovered from the portal vein. After concluding this stage, the stomach was isolated from the other organs and its internal and external surfaces were washed in running water. It was then opened up at the greater curvature to allow its mucous surfaces to be studied.

The areas where staining had not occurred were photographed and then measured by means of three morphometric methods: millimeter squares, planimetry and computerized morphometry. In the millimeter squares method, the total area of the mucous surface and the areas lacking staining were subdivided into square millimeters $\left(\mathrm{mm}^{2}\right)$, thereby establishing the relationship between them, expressed as a percentage. In the second method, a planimeter was utilized (Amsler, model 612, USA), to measure the total area and those lacking staining in the same way, establishing the percentage relationship between them. In the computerized morphometry method, the total area and those lacking staining were measured by means of a CAD computer graphics program (Micro Station, Bentley Systems, USA), and the percentage relationship between the areas was established in the same way.

To compare the groups of animals in which areas lacking staining were formed, the Mann-Whitney test (U-test) was applied as a non-parametric test aimed at comparing two independent samples. The level for rejection of the null hypothesis was set at $0.05 \%$, with values of statistical significance being marked with an asterisk.

With the aim of analyzing the concordance between the three methods employed for measuring the areas, the Batko interclass correlation index and the Kruskal-Wallis test with two degrees of freedom were applied.

\section{RESULTS}

In group A, all animals presented uniform distribution of the staining substance along the gastric mucous surface. There was no formation of areas lacking staining and therefore the methods proposed for calculating such areas were not applied (Figure 1).

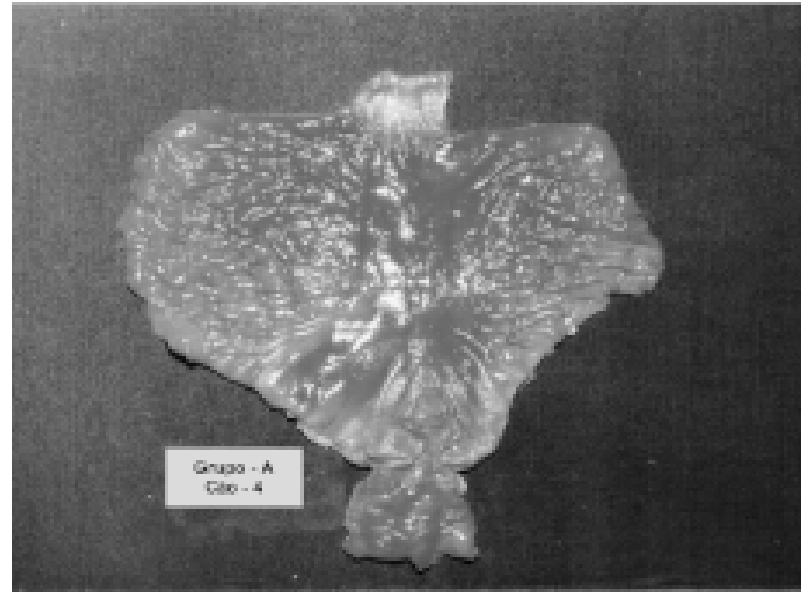

FIGURE 1 - Gastric mucosa without areas lacking staining for dogs of control group (Group A).

In group B, areas lacking staining were formed in all animals, invariably located at the lesser curvature and on part of the anterior and posterior walls of the gastric corpus (Figure 2).

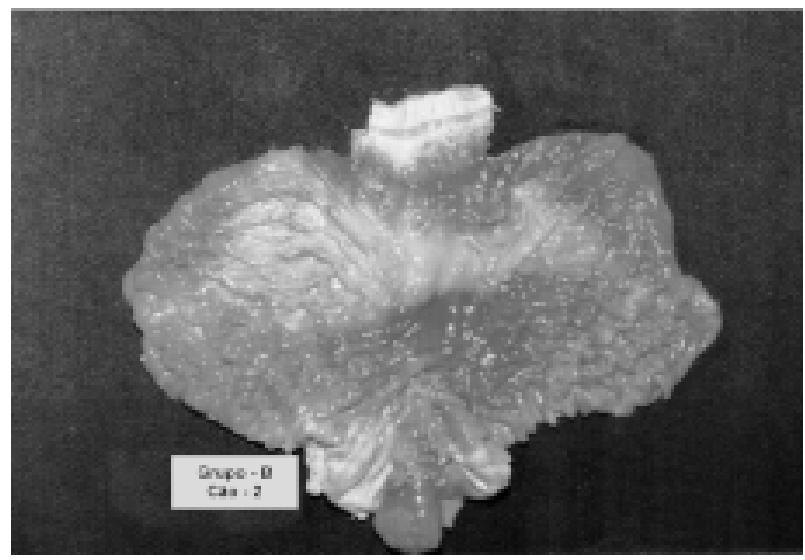

FIGURE 2 - Area lacking staining in lesser-curve gastric mucosa of dogs undergoing proximal gastric vagotomy alone (Group B).

The areas lacking staining varied in shape and dimensions from animal to animal, although they always had the same localization. It was seen that the area lacking staining represented an average of $29.2 \%$ of the total mucous surface

When the measurement was made by means of the planimetry method, it was observed that the area lacking staining represented $29.6 \%$ of the organ total area. The measurement by means of computerized morphometry indicated that the area lacking staining represented $32.4 \%$ of the gastric mucous surface.

In group $\mathrm{C}$, all the animals forming the group presented areas lacking staining, located at the lesser 
curvature of the stomach, along the corpus walls and in part of the gastric antrum. In the same way as in the preceding group, the size and shape varied from animal to animal, although the localization was always the same (Figure 3).

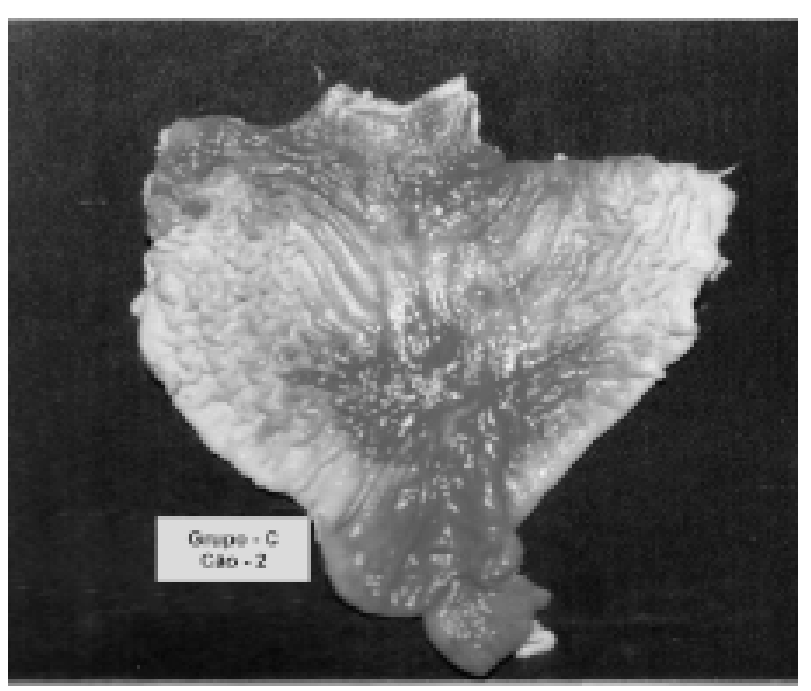

FIGURE 3 - Area lacking staining in lesser-curve gastric mucosa of dogs undergoing splenectomy in association with proximal gastric vagotomy (Group C).
In the measurement of the total area and areas lacking staining, as well as the relationship between them, when the millimeter squares method was utilized, it was observed that the area lacking staining represented an average of $58.8 \%$ of the total mucous surface.

When the planimetry method was employed, it was seen that the area lacking staining represented $58.2 \%$ of the total mucous surface.

Measurement using computerized morphometry showed that the area lacking staining represented $58.4 \%$ of the whole gastric mucous surface.

In group $\mathrm{D}$, in the same way as for the control group, the gastric mucous surface presented uniform staining in all animals, and no areas lacking staining were seen.

A comparison of the results from animals in groups $\mathrm{B}$ and $\mathrm{C}$ revealed that, independent of the calculation method utilized, the area lacking staining was significantly greater in the animals that underwent PGV in association with splenectomy in comparison with those that underwent PGV alone (Tables 1, 2 and 3).

TABLE 1 - Total area and areas lacking staining $\left(\mathrm{mm}^{2}\right)$ and their relationship as a percentage, as evaluated by means of the millimeter squares method, for dogs undergoing proximal gastric vagotomy alone (group B) and dogs undergoing proximal gastric vagotomy in association with splenectomy (group C).

\begin{tabular}{ccccccc}
\hline Dog & \multicolumn{2}{c}{$\begin{array}{c}\text { Total area } \\
\left(\mathbf{m m}^{2}\right)\end{array}$} & \multicolumn{2}{c}{$\begin{array}{c}\text { Area lacking staining } \\
\left(\mathbf{m m}^{2}\right)\end{array}$} & \multicolumn{2}{c}{$\begin{array}{c}\text { Relationship } \\
(\boldsymbol{\%})\end{array}$} \\
\hline & Group B & Group C & Group B & Group C & Group B & Group C \\
\hline 1 & 4919 & 3165 & 2329 & 2305 & 47.34 & 72.82 \\
2 & 4398 & 3464 & 866 & 1533 & 19.69 & 44.25 \\
3 & 3785 & 3379 & 1155 & 2352 & 30.51 & 69.60 \\
4 & 4538 & 3339 & 1224 & 2842 & 26.97 & 85.11 \\
5 & 4279 & 5281 & 1381 & 3504 & 32.27 & 66.35 \\
6 & 4682 & 2841 & 1791 & 1516 & 38.25 & 53.36 \\
7 & 4074 & 5358 & 1052 & 2292 & 25.82 & 42.77 \\
8 & 3959 & 3873 & 1061 & 1188 & 26.79 & 30.67 \\
9 & 3658 & 5512 & 632 & 3589 & 15.96 & 65.11 \\
\hline
\end{tabular}

$\mathrm{mm}^{2}=$ square millimeters

$\%=$ percentage

Mann-Whitney Rank Sum Test

$\mathrm{N}=9$

$\mathrm{T}=50,000 ; \mathrm{n}($ small $)=9 ; \mathrm{n}(\mathrm{big})=9 ;(\mathrm{P}=0.002) * *$ significant 
TABLE 2 - Total area and areas lacking staining $\left(\mathrm{mm}^{2}\right)$ and their relationship as a percentage, as evaluated by means of the planimetry method, for dogs undergoing proximal gastric vagotomy alone (group B) and dogs undergoing proximal gastric vagotomy in association with splenectomy (group C).

\begin{tabular}{ccccccc}
\hline Dog & \multicolumn{2}{c}{$\begin{array}{c}\text { Total area } \\
\left(\mathbf{m m}^{2}\right)\end{array}$} & \multicolumn{2}{c}{$\begin{array}{c}\text { Area lacking staining } \\
\left(\mathbf{m m}^{\mathbf{2}}\right)\end{array}$} & \multicolumn{2}{c}{$\begin{array}{c}\text { Relationship } \\
(\boldsymbol{\%})\end{array}$} \\
\hline & Group B & Group C & Group B & Group C & Group B & Group C \\
\hline 1 & 4883 & 3193 & 2480 & 2366 & 50.78 & 74.09 \\
2 & 4223 & 3506 & 853 & 1463 & 20.19 & 41.72 \\
3 & 3703 & 3583 & 1120 & 2616 & 30.24 & 73.01 \\
4 & 4393 & 3456 & 1243 & 2920 & 28.29 & 84.49 \\
5 & 4260 & 4690 & 1273 & 2993 & 29.88 & 63.81 \\
6 & 4686 & 2743 & 1766 & 1493 & 37.68 & 54.42 \\
7 & 4022 & 5122 & 1037 & 2123 & 25.78 & 41.44 \\
8 & 3998 & 3711 & 1092 & 1072 & 27.31 & 28.88 \\
9 & 3612 & 5420 & 614 & 3399 & 16.99 & 62.71 \\
\hline
\end{tabular}

$\mathrm{mm}^{2}=$ square millimeters

$\%=$ percentage

Mann-Whitney Rank Sum Test

$\mathrm{N}=9$

$\mathrm{T}=51,000 ; \mathrm{n}($ small $)=9 ; \mathrm{n}(\mathrm{big})=9 ;(\mathrm{P}=0.003) * *$ significant

TABLE 3 - Total area and areas lacking staining $\left(\mathrm{mm}^{2}\right)$ and their relationship as a percentage, as evaluated by means of the computerized morphometry method, for dogs undergoing proximal gastric vagotomy alone (group B) and dogs undergoing proximal gastric vagotomy in association with splenectomy (group C).

\begin{tabular}{ccccccc}
\hline Dog & \multicolumn{2}{c}{$\begin{array}{c}\text { Total area } \\
\left(\mathbf{m m}^{2}\right)\end{array}$} & \multicolumn{2}{c}{$\begin{array}{c}\text { Area lacking staining } \\
\left(\mathbf{m m}^{\mathbf{2}}\right)\end{array}$} & \multicolumn{2}{c}{$\begin{array}{c}\text { Relationship } \\
(\boldsymbol{\%})\end{array}$} \\
\hline & Group B & Group C & Group B & Group C & Group B & Group C \\
\hline 1 & 4752 & 3485 & 2570 & 2615 & 54.08 & 75.03 \\
2 & 4301 & 3795 & 1047 & 1583 & 24.34 & 41.71 \\
3 & 5397 & 3692 & 1821 & 2638 & 33.74 & 71.45 \\
4 & 4683 & 3491 & 1454 & 2818 & 31.04 & 80.72 \\
5 & 4560 & 4780 & 1566 & 2972 & 34.34 & 62.17 \\
6 & 4569 & 2763 & 1758 & 1490 & 38.47 & 53.92 \\
7 & 4480 & 5146 & 1194 & 2287 & 26.65 & 44.44 \\
8 & 3954 & 3745 & 1177 & 1193 & 29.76 & 31.85 \\
9 & 3744 & 5710 & 737 & 319 & 19.68 & 65.13 \\
\hline
\end{tabular}

$\mathrm{mm}^{2}=$ square millimeters

$\%=$ percentage

Mann-Whitney Rank Sum Test

$\mathrm{N}=9$

$\mathrm{T}=52,000 ; \mathrm{n}($ small $)=9 ; \mathrm{n}(\mathrm{big})=9 ;(\mathrm{P}=0.004) * *$ significant

A comparison was made of the results obtained from the three morphometric methods employed, by means of the Batko interclass correlation index. This revealed that there was excellent concordance between them in relation to calculations of the total area and areas lacking staining for animals belonging to groups B and C (Tables 5, 6 and 7). Only in the calculation of the total area for animals belonging to group B was this interclass correlation analysis just good (Table 4). 
TABLE 4 - Comparison between the millimeter squares, planimetry and computerized morphometry methods for the measurement of the total area in the animals undergoing proximal gastric vagotomy alone (group B).

\begin{tabular}{cccc}
\hline Dog & \multicolumn{3}{c}{ TOTALAREA $\left(\mathbf{m m}^{\mathbf{2}}\right)$} \\
\hline & Millimeter Squares & Planimetry & Computerized Morphometry \\
\hline 1 & 4919 & 4883 & 4752 \\
2 & 4398 & 4223 & 4301 \\
3 & 3785 & 3703 & 5387 \\
4 & 4538 & 4393 & 4683 \\
5 & 4279 & 4260 & 4560 \\
6 & 4682 & 4686 & 4569 \\
7 & 4074 & 4022 & 4480 \\
8 & 3959 & 3998 & 3954 \\
9 & 3658 & 3612 & 3744 \\
\hline
\end{tabular}

$\mathrm{mm}^{2}=$ square millimeters

Concordance analysis: Batko Interclass Correlation Index

$\mathrm{n}=9$

Total area: $\mathrm{R}=0.74633775 \quad$ (good concordance)

TABLE 5 - Comparison between the millimeter squares, planimetry and computerized morphometry methods for the measurement of the area lacking staining in the animals undergoing proximal gastric vagotomy alone (group B).

\begin{tabular}{cccc}
\hline Dog & \multicolumn{3}{c}{ AREA LACKINGSTAINING $\left(\mathbf{m m}^{2}\right)$} \\
\hline & Millimeter Squares & Planimetry & Computerized Morphometry \\
\hline 1 & 2329 & 2480 & 2570 \\
3 & 866 & 853 & 1047 \\
4 & 1155 & 1120 & 1821 \\
5 & 1224 & 1243 & 1454 \\
6 & 1381 & 1273 & 1566 \\
7 & 1791 & 1766 & 1758 \\
8 & 1052 & 1037 & 1194 \\
9 & 1061 & 1092 & 1177 \\
\hline
\end{tabular}

$\mathrm{mm}^{2}=$ square millimeters

Concordance analysis: Batko Interclass Correlation Index

$\mathrm{N}=9$

Area lacking staining: $\quad \mathrm{R}=0.984386 \quad$ (excellent concordance)

TABLE 6-Comparison between the millimeter squares, planimetry and computerized morphometry methods for the measurement of the total area in the animals undergoing proximal gastric vagotomy in association with splenectomy (group C).

\begin{tabular}{cccc}
\hline Dog & \multicolumn{3}{c}{ TOTAL AREA $\left(\mathbf{m m}^{2}\right)$} \\
\hline & Millimeter Squares & Planimetry & Computerized Morphometry \\
\hline 1 & 3165 & 3193 & 3458 \\
2 & 3464 & 3506 & 3795 \\
3 & 3379 & 3583 & 3692 \\
4 & 3339 & 3456 & 3491 \\
5 & 5281 & 4690 & 4780 \\
6 & 2841 & 2743 & 2763 \\
7 & 5358 & 5122 & 5146 \\
8 & 3873 & 3711 & 3745 \\
9 & 5512 & 5420 & 5710 \\
\hline
\end{tabular}

$\mathrm{mm}^{2}=$ square millimeters

Concordance analysis: Batko Interclass Correlation Index

$\mathrm{N}=9$

Total area: $\mathrm{R}=0.9918201 \quad$ (excellent concordance) 
TABLE 7 - Comparison between the millimeter squares, planimetry and computerized morphometry methods for the measurement of the area lacking staining in the animals undergoing proximal gastric vagotomy in association with splenectomy (group C).

\begin{tabular}{cccc}
\hline Dog & \multicolumn{3}{c}{ AREA LACKING STAINING $\left.\mathbf{( m m}^{2}\right)$} \\
\hline & Millimeter Squares & Planimetry & $\begin{array}{c}\text { Computerized } \\
\text { Morphometry }\end{array}$ \\
\hline 1 & 2305 & 2366 & 2615 \\
2 & 1533 & 1463 & 1583 \\
3 & 2352 & 2616 & 2638 \\
4 & 2842 & 2920 & 2818 \\
5 & 3504 & 2993 & 2972 \\
6 & 1516 & 1493 & 1490 \\
7 & 2292 & 2123 & 2287 \\
8 & 1188 & 1072 & 1193 \\
9 & 3589 & 3399 & 3719 \\
\hline
\end{tabular}

$\mathrm{mm}^{2}=$ square millimeters

Concordance analysis: Batko Interclass Correlation Index

$\mathrm{N}=9$

Area lacking staining: $\quad \mathrm{R}=0.9906606$ (excellent concordance)

The Kruskal-Wallis test showed that there were methods employed for calculating the total area and no statistically significant differences between the three the areas lacking staining (Tables 8 and 9).

TABLE 8 - Comparison between the results from the millimeter squares, planimetry and computerized morphometry methods in the evaluation of the total area of the gastric mucous surface and the areas lacking staining, and the percentage relationships between them, in dogs undergoing proximal gastric vagotomy alone (group B), using the Kruskal-Wallis test.

\begin{tabular}{cccccc}
\hline Method & $\mathbf{n}$ & "Missing” & Average & $\mathbf{2 5 \%}$ & $\mathbf{7 5 \%}$ \\
\hline Millimeter squares & 9 & 0 & 26.970 & 24.287 & 33.765 \\
Planimetry & 9 & 0 & 28.280 & 24.383 & 32.100 \\
Computerized & 9 & 0 & 31.050 & 26.070 & 35.362 \\
Morphometry & & & & & \\
\hline
\end{tabular}

$\mathrm{N}=$ number of animals

Normality test: $(\mathrm{P}=0.060)$

Equal variance test: $(\mathrm{P}=0.997)$

$\mathrm{H}=0.677$ (with two degrees of freedom). $(\mathrm{P}=0.713)$

TABLE 9 - Comparison between the millimeter squares, planimetry and computerized morphometry methods in the evaluation of the total area of the gastric mucous surface and the areas lacking staining, and the percentage relationships between them, in dogs undergoing proximal gastric vagotomy in association with splenectomy (group C), using the Kruskal-Wallis test.

\begin{tabular}{cccccc}
\hline Method & n & "Missing" & Average & $\mathbf{2 5 \%}$ & $\mathbf{7 5 \%}$ \\
\hline Millimeter Squares & 9 & 0 & 65.110 & 43.880 & 70.405 \\
Planimetry & 9 & 0 & 62.710 & 41.650 & 73.280 \\
Computerized & 9 & 0 & 62.160 & 43.758 & 72.350 \\
Morphometry & & & & & \\
\hline
\end{tabular}

$\mathrm{N}=$ number of animals

Normality test: $(\mathrm{P}=0.179)$

Equal variance test: $(\mathrm{P}=0.979)$

$\mathrm{H}=0.0317$ (with two degrees of freedom). $(\mathrm{P}=0.984)$ 


\section{DISCUSSION}

The etiopathogenesis of necrosis of the lesser curvature after PGV is controversial and it is believed that two origins can be considered: inadvertent ligature of segments of the gastric wall at the time of performing the operation ${ }^{9,10,11}$ and the ischemia that the technique imposes on the region ${ }^{4}$. Experimental studies have demonstrated that the inadvertent involvement of segments of the gastric wall during the ligature of vesselnerve branches heading towards the lesser curvature may evolve to necrosis and later perforation as a result of the ischemia ${ }^{9,10,11}$. This theory was revived consequent to observations that inadvertent ligature might explain cases of necrosis that occurred after splenectomy alone ${ }^{6}$. Nonetheless, this explanation on its own does not explain all the cases of necrosis of the lesser curvature.

The intramural irrigation of the gastric wall in the region of the lesser curvature is not done in the same way as for the remainder of the organ. Whereas in other regions the vessels coming from the main arteries form a rich blood plexus when they reach the submucous layer, in the region of the lesser curvature they cross the gastric wall without forming the submucous plexus, thereby directly irrigating the mucosa of the organ. There is thus the formation of a strip of approximately $3 \mathrm{~cm}$ along the lesser curvature and on parts of the anterior and posterior walls of the gastric corpus that has circulation of terminal type, potentially subject to ischemic phenomena.

The deficiencies in the circulation at the lesser curvature after $\mathrm{PGV}$ have been confirmed experimentally ${ }^{12,13}$. A comparison between PGV techniques that preserve the irrigation at the lesser curvature and the conventional technique has shown that there is better blood supply when the vascularization is preserved ${ }^{14}$. The role of ischemia in the genesis of necrosis of the lesser curvature becomes more evident when we see the possibilities for this phenomenon to occur among patients undergoing embolization of the left gastric artery in the treatment of hemorrhage. In this situation, the gastric wall does not undergo any traumatic event and the necrosis may occur precisely at the lesser curvature.

The results obtained from the present study reinforce these impressions. When analyzing the animals of group B, in which the PGV was performed alone, areas lacking staining were found in the region of the lesser curvature and on part of the anterior and posterior walls of the gastric corpus, precisely in the area most susceptible to ischemic phenomena. It is evident that, even without there being inadvertent ligatures of the gastric wall with consequent evolution to necrosis and perforation, PGV induces a diminution of blood irrigation at the lesser curvature. This blood deprivation not only occurs because of the direct interruption of the flow but also because the vagotomy induces the opening up of arteriovenous anastomoses located in the gastric submucosa, thereby diminishing the local perfusion.

Maintaining the viability of the gastric wall at the lesser curvature is thought to be dependent on compensation coming from other localities in the gastric wall. Among the arteries that have importance in furnishing a compensatory supply, the left gastroepiploic artery, the short vessels and the posterior gastric artery merit a prominent position ${ }^{12,13}$. These arteries may originate in the distal portions of the splenic artery and if so, performing a splenectomy could interrupt the blood flow to these vessels in a considerable number of cases.

This being so, for a stomach undergoing PGV and consequent deprival of its main blood supply from the left and right gastric arteries, the possibility of ischemia could increase when an additional deficiency is caused by splenectomy ${ }^{15}$. The results from the present study corroborate these suppositions, since in the comparison of groups B and $\mathrm{C}$ it was noted that the area susceptible to ischemic phenomena increased significantly.

The results from this study suggest that the association of PGV and splenectomy is hazardous because of the possibility that areas potentially subject to ischemic phenomena may arise. Although PGV is an operation only occasionally performed, it must not be forgotten that during the 1970s and 1980s it was performed on a considerable number of patients for treatment of duodenal ulcers.

Nowadays, with the increase in urban violence, the opportunities of abdominal trauma with the possibility of splenic lesion are becoming more frequent. The results from this study suggest that special care must be taken with patients who previously underwent PGV and may require splenectomy. In this situation, the occurrence of ischemic complications would be a real possibility. To minimize the risks of gastric necrosis, splenectomy should be performed at the hilum of the organ, with the aim of avoiding the ligature of the left gastroepiploic artery, posterior gastric artery and the short vessels. The best surgical option in such cases is to attempt conservative measures that avoid splenectomy, and when this is not possible, partial extirpation of the spleen may be indicated.

Because splenectomy after PGV significantly increases the possibility for gastric necrosis when these 
operations are carried on simultaneously or successively, careful postoperative follow-up needs to be instituted.

\section{CONCLUSION}

Total splenectomy after PGV significantly increases the possibility for ischemic necrosis in the lesser gastric curvature when these operations are carried on simultaneously or successively.

\section{REFERENCES}

1. Isabella V, Marotta E, Bianchi F. Ischemic necrosis of proximal gastric remnant following subtotal gastrectomy with splenectomy. J Surg Oncol 1984;25:124-32.

2. Skarstein A, Lekven J. Influence of gastric banding on stomach blood supply with or without concurrent splenectomy. Am J Surg 1985;149:351-6.

3. Kennedy T, Magill P, Johnston GW, Parks TG. Proximal gastric vagotomy, fundoplication and lesser-curve necrosis. Br Med J $1979 ; 1: 1455-6$.

4. Barroso FL, Ornellas Filho A. Inquérito Nacional sobre vagotomia superseletiva (VSS). Revisão de 3.515 casos. Rev Col Bras Cir 1980;7:23-34.

5. Halvorsen JF, Heimann P, Solhaug JH, Jacobsen KB. Localized avascular necrosis of lesser curve of stomach complicating highly selectively vagotomy. Br Med J 1975;2:590-1.

6. Harrison BF, Clanges E, Sparkman RS. Gastric fistula folowing splenectomy: its cause and prevention. Ann Surg $1977 ; 185: 210-3$
7. Martinez CAR, Waisberg J, Palma RT, Bromberg SH, Castro MAP, Santos PA Gastric necrosis and perforation as a complication of splenectomy. Case report and related references. Arq Gastroent 2000;37:227-30.

8. Pan Chacon J, Kobata CM. Análise crítica de resultados da vagotomia superseletiva após 5 anos. Inquérito Nacional. Rev Col Bras Cir 1986;13:110-4.

9. Kobayasi S, Mendes EF. Lesões ulceradas do estômago após vagotomia gástrica proximal (VGP): estudo experimental em cães. Acta Cir Bras 1992;7:128-132.

10. Kobayasi S, Rodrigues MAM, Montenegro MRG. Irrigação da pequena curvatura gástrica no cão após vagotomia gástrica proximal. Avaliação pela arteriografia pós-morte e pelo estudo das alterações histopatológicas. Rev Hosp Clin Fac Med S Paulo 1982; 37:114-20.

11. Kobayasi S, Rodrigues MAM, Montenegro RG, Macedo MRG, Hossne WS, Mendes EF. Necrose da pequena curvatura gástrica após vagotomia gástrica proximal por traumatismo da parede gástrica. Estudo experimental em cães. Rev Hosp Clin Fac Med S Paulo 1984;39:96-100.

12. Marchesini JB, Silva ITC, Bueno LAG, Artigas GV, Leitão JT, Fronza Jr. E. Circulação da pequena curvatura após a vagotomia superseletiva. Rev Col Bras Cir 1980;7:9-12.

13. Marchesini JB, Bueno LAG, Silva ITC. Estudo em molde vinílico da vascularização da pequena curvatura do estômago após vagotomia superseletiva. Rev Col Bras Cir 1981;8:298-301.

14. Bakonyi Neto A. Estudo da vascularização do estômago após a vagotomia gástrica proximal isolada ou associada à antrectomia [Tese-Mestrado]. Universidade Federal de São Paulo - Escola Paulista de Medicina;1983.

15. Barone CA, Andrade A, Silva Fillho AC. Angiografia "postmorten" da circulação da curvatura gástrica menor em estômagos íntegros, após VSS convencional e após VSS com preservação de vasos. Hosp Ensino Rev 1981; 8:181-195. 
Martinez CAR, Waisberg J, Palma RT, Silva FZ, Cimerman G, Goffi, FS. Estudo morfométrico da mucosa gástrica de cães submetidos à vagotomia gástrica proximal, esplenectomia ou vagotomia gástrica proximal associada com esplenectomia. Acta Cir Bras [serial online] 2002 Set-Out; 17(5). Disponível em URL: http://www.scielo.br/acb.

RESUMO - Objetivo: Avaliar os efeitos da esplenectomia total e da vagotomia gástrica proximal (VGP) isoladas e associadas sobre a vascularização gástrica. Métodos: Utilizaram-se 28 cães, distribuídos em quatro grupos: grupo A, laparotomia e manipulação gástrica; grupo B, VGP; grupo $\mathrm{C}, \mathrm{VGP}$ associada à esplenectomia; grupo $\mathrm{D}$, esplenectomia isolada. Todos os animais foram mortos no $7^{\circ}$ pós-operatório e imediatamente infundiu-se o corante na aorta torácica. O estômago aberto pela grande curvatura foi fotografado. Na superfície mucosa gástrica, a formação de áreas coradas e desprovidas de coloração foi mensurada por três métodos: decomposição milimétrica, planimétrico e morfometria computadorizada. Resultados: Verificou-se nos grupos B e C formação de área desprovida de coloração na pequena curvatura gástrica, sendo significativamente maior no grupo $\mathrm{C}$ $(\mathrm{p}<0,05)$. Nos grupos A e D tais áreas não foram observadas. A análise estatística não revelou diferenças significativas entre os resultados dos três métodos utilizados. Conclusões: Nas condições desse estudo os resultados permitiram concluir que nos animais com o estômago íntegro e naqueles onde a esplenectomia foi realizada de forma isolada, a vascularização do estômago permitiu a perfusão de toda a superfície do órgão. Nos animais submetidos a VGP isolada e principalmente quando a VGP foi associada ã esplenectomia ocorreu significativa diminuição do suprimento sangüíneo na curvatura gástrica menor, sugerindo a potencialidade isquêmica dessa região.

DESCRITORES - Esplenectomia. Vagotomia gástrica proximal. Estômago.

Conflito de interesse: nenhum Fontes de financiamento: nenhuma

Address for correspondence:

Dr. Carlos Augusto Real Martinez

Rua Rui Barbosa 255/32

09190-370 Santo André - SP

Telefone: (11) 4992-5955

cao@attglobal.net

Data do recebimento: 8/05/2002

Data da revisão: 11/06/2002

Data da aprovação: 25/07/2002 